\title{
Structure of the meso-Diaminopimelic Acid Containing Peptidoglycans in Escherichia coli B and Bacillus megaterium $\mathrm{KM}^{*}$
}

Jean van Heijenoort, Lydia Elbaz, Philippe Dezélée, Jean-François Petit, Evanghelos Bricas, and Jean-Marie Ghuysen

ABSTRACT: The peptide subunit of the peptidoglycan of the envelope of Escherichia coli $\mathrm{B}$ has the sequence L-Ala- $\gamma$-D-Glu-(L)-meso-diaminopimelic acid-(L)-D-Ala. D-Ala-(D)-meso diaminopimelic acid linkages are involved in the cross-linking between peptide subunits. A major part of the wall peptidoglycan of Bacillus megaterium KM is composed of the same aforementioned peptide subunits and peptide cross-linkages. In this latter case, however, the D-Ala-(D)-meso-diaminopimelic acid linkages are not the only important ones. As previously shown, about $15 \%$ of the diaminopimelic acid residues

$T_{\text {n }}$ he peptidoglycan portion of the envelope of $E_{s}$ cherichia coli is a thin layer, $20-30 \AA$ thick, sandwiched between the underlying plasma membrane and an enormous multiple track layer of lipoprotein and lipopolysaccharide (Murray et al., 1965). Weidel and his colleagues (Weidel and Pelzer, 1964) were the first to succeed in isolating this peptidoglycan as a "rigid layer," i.e., a sacculus with protein globules attached to it as tuftlike appendages. Subsequently, these proteins could be removed by protease treatment. The isolated peptidoglycan was shown to contain two main elements: (1) disaccharide peptide monomers: $N$-acetylglucosaminyl$N$-acetylmuramyl-L-Ala-D - Glu - meso-diaminopimelic

* From the Service de Bactériologie, Université de Liège, Liège, Belgium, and Institut de Biochimie, Faculté des Sciences, 91, Orsay, France. Received August 1, 1968. This research has been supported in part by Grant UR-E4-10-2 made by the U.S. Department of Agriculture under Public Law 480. are $\mathrm{DD}$ and they seem to be involved in another type of peptide cross-linkage. Streptomyces KM endopeptidase solubilizes the walls of Bacillus megaterium. Although this enzyme is not lytic upon Escherichia coli envelope, it liberates disaccharide peptide monomer from a bisdisaccharide peptide dimer, isolated from the same envelope. This dimer is composed of two $\beta$ 1,4- $N$-acetylglucosaminyl- $N$-acetylmuramyl-L-Ala - $\gamma$ D-Glu-(L)-meso-diaminopimelic acid-(L)-D-Ala units, joined by a D-Ala-(D)-meso-diaminopimelic acid linkage.

acid-D-Ala; ${ }^{1}$ some of these lack the terminal D-Ala residue, probably as a consequence of the action of an autolytic carboxypeptidase (Pelzer, 1963); and (2) bisdisaccharide peptide dimers in which two dischaccharide peptide monomers are joined by a peptide linkage involving one amino group of meso-diaminopimelic acid. In situ, the peptidoglycan was visualized as a monolayer network. Glycan strands are substituted by peptide subunits of which about $50 \%$ are cross-linked to form dimers so that the disaccharide units of two adjacent chains are paired.

\footnotetext{
${ }^{1}$ In order to specify on which one of the two asymmetric carbons of meso-diaminopimelic acid are placed the substituted amino groups, we advocate the use of the notation (L) or (D) written immediately before meso-diaminopimelic acid. Similarly we propose the use of (L) or (D) immediately after meso-diaminopimelic acid to distinguish between the carboxyl-substituted groups.
} 
The wall peptidoglycan of the gram-positive Bacillus megaterium KM presents many similarities to that of E. coli: (1) tetrapeptides L-Ala-D-Glu-(L)-meso-diaminopimelic acid-D-Ala and tripeptides L-Ala-D-Glu-(L)meso-diaminopimelic acid are the peptide subunits, and (2) a low degree of peptide cross-linking involving one amino group of meso-diaminopimelic acid occurs throughout the network (Bricas et al., 1967). In contrast to the $E$. coli peptidoglycan, however, that of $B$. megaterium represents $50 \%$ of the weight of the isolated walls. It is about $100 \AA$ thick and it is most probably a multilayered structure. Furthermore, about $15 \%$ of the total diaminopimelic acid residues are DD (Bricas et al., 1967). These latter residues both have amino groups which are unavailable for dinitrophenylation and they probably play an important role in maintaining the rigidity of the net.

Difficulties in the study of the detailed structure of meso-diaminopimelic acid containing peptidoglycans arise, of course, from the fact that meso-diaminopimelic acid presents potentialities for peptide linkages either with the functions adjacent to its D-asymmetric carbon or with those adjacent to its L-asymmetric carbon. Recently, it has been shown by Diringer and Jušic (1966) in $E$. coli and by Bricas et al. (1967) in B. megaterium that the amino group of meso-diaminopimelic acid linked to glutamic acid was located on the L-asymmetric carbon and, consequently, that the amino group involved in peptide cross-linking was located on the D-asymmetric carbon.

The experiments presented in this paper deal with (1) the nature of the carboxyl group ( $\alpha$ or $\gamma$ ) of the glutamic acid linked to the amino group on the $\mathrm{L}$ carbon of mesodiaminopimelic acid, (2) the determination of which carboxyl group of meso-diaminopimelic acid is substituted by the terminal D-Ala residue, (3) the nature of the carboxyl group involved in the peptide cross-linking to the amino group on the D-carbon of meso-diaminopimelic acid. In the case of $B$. megaterium, the study is thus limited to that portion of the peptidoglycan containing meso-diaminopimelic acid and no DD-diaminopimelic acid.

\section{Materials and Methods}

Soluble Wall or Envelope Compounds. 1. WaLLS of B. megaterium. A preparation of disaccharide peptide monomers, the diaminopimelic acid residues of which are all meso, was used for the isolation of peptide monomer subunits. This preparation was that previously obtained by Bricas et al. (1967).

2. ENVELOPES of E. coli. E. coli B was grown, at $37^{\circ}$, with shaking, in $\mathrm{M}_{3}$ antibiotic Difco medium. The cells were harvested at the end of the log phase. The rigid layer was prepared according to technique B described by Pelzer (1965); yield $3 \mathrm{~g}$ (dry weight) of rigid layer from $500 \mathrm{~g}$ of cells (wet weight). The rigid layer preparation $(2.8 \mathrm{~g})$ was suspended in $500 \mathrm{ml}$ of $0.025 \mathrm{M}$ phosphate buffer ( $\mathrm{pH} \mathrm{6.6)}$ and incubated with $112 \mathrm{mg}$ of eggwhite lysozyme for $20 \mathrm{hr}$ at $37^{\circ}$. After centrifugation, virtually all of the diaminopimelic acid residues were found in the supernatant which was lyophilized.
Enzymes. Streptomyces $N$-acetylmuramyl-L-alanine amidase and Streptomuces KM endopeptidase were prepared as described by Ghuysen et al. (1969).

Synthetic Compounds. The two isomeric tripeptides LAla- $\alpha$-D-Glu-(L)-meso-diaminopimelic acid and L-Ala- $\gamma$ D-Glu-(L)-meso-diaminopimelic acid were used as models for the determination of the structure of the natural tripeptides isolated. Their synthesis has been reported elsewhere (Dezélée, 1968). The peptide meso-diaminopimelic acid-(D)-L-Ala was used as a model for the Edman degradation and the peptide L-Ala-(D)-meso-diaminopimelic acid-(D)-L-Ala as a model for the C-terminal group determination by hydrazinolysis. The preparation of these two peptides has been described in previous papers (Bricas et al., 1962; Bricas and Nicot, 1965). The $\alpha$-hydrazide of glutamic acid was prepared according to the procedure of Le Quesne and Young (1950).

Analytical Methods. Reducing groups (Park-Johnson procedure), acetamido sugars (Morgan-Elson reaction), amino acids (fluorodin trobenzene technique and/or by analyses with a Technicon apparatus), D-alanine (enzymatic procedure) and $\mathrm{N}$ - and C-terminal groups (fluorodinitrobenzene and hydrazinolysis techniques, respectively) were measured as previously described (Ghuysen et al., 1966, 1968). Yields of hydrazinolysis are not corrected and are expressed relative to an alanine standard which was subjected to identical conditions. Edman degradations were carried out as described by Tipper et al. (1967) and Ghuysen et al. (1967).

Electrophoresis. Preparative electrophoreses were carried out on Whatman No. 3MM paper using a Savant instruments apparatus (Savant instruments Inc., Hickeville, N. Y.) or an Electrorheophor apparatus (Pleuger, Antwerp, Belgium) at $\mathrm{pH} 1.9$ in $2 \%$ formic acid (Savant instruments apparatus), $\mathrm{pH} 2.5$ in $0.1 \mathrm{~N}$ formic acid (Pleuger apparatus), pH 4 in water-pyridine-acetic acid $(976: 6: 23, \mathrm{v} / \mathrm{v}$ ) (Savant instruments apparatus, and 1000:2.5:9, v/v) (Pleuger apparatus), and pH 6.4 in water-pyridine-acetic acid (900:100:4, v/v) (Savant Instruments apparatus).

Chromatographic Solvents. The following solvents were used: (I) 1-butanol-acetic acid-pyridine-water $(60: 17: 3: 20, \mathrm{v} / \mathrm{v})$; (II) 1-butanol-acetic acid-pyridinewater $(30: 6: 20: 24, v / v) ;$ (III) 1-butanol-acetic acid-water (40:10:50, v/v upper phase). Chromatography was performed on thin-layer plates $(0.3-0.4 \mathrm{~mm})$ of MN-Cellulose $300 \mathrm{HR}$, Macherey, Nagel and Co.

\section{Experimental Section}

Isolation of Tripeptide L-Ala- $\gamma-\mathrm{D}-\mathrm{Glu}-(\mathrm{L})-$ meso-diaminopimelic acid, of Tetrapeptide $\mathrm{L}-\mathrm{Ala}-\gamma-\mathrm{D}-\mathrm{Glu}-(\mathrm{L})-$ meso-diaminopimelic acid-(L)-D-Ala, and of Bisdisaccharide Peptide Dimer. A. From B. megaterium. The disaccharide peptide monomer preparation (see Material and Methods) was shown to be mainly composed of two distinct compounds by cellulose thin-layer chromatography in solvent III (two successive migrations). Preparative separation of these two disaccharide peptide monomers was not attempted by this procedure. The original disaccharide peptide monomer fraction (50 mg) was treated with $N$-acetylmuramyl-L-alanine 
amidase (Bricas et al., 1967). A purified mixture of the free peptides and the free disaccharide units was obtained by gel filtration in $0.1 \mathrm{M} \mathrm{LiCl}$ on the linked Sephadex G-50-Sephadex G-25 columns (Ghuysen et al., 1968) and was desalted by filtration in water on a Sephadex G-25 column $(115 \mathrm{~cm} / 1.5 \mathrm{~cm})$. After lyophilization, the tripeptide, tetrapeptide, and disaccharide were separated from each other by preparative chromatography on cellulose plates. In order to ensure a good separation, $100 \mu \mathrm{l}$ of an aqueous solution of the original mixture ( $5 \mathrm{~m} \mu$ equiv $/ \mu \mathrm{l}$, expressed in glutamic acid) were spotted on each of the $20 \times 20 \mathrm{~cm}$ plates. Plates were developed with solvent II, dried, and developed again with the same solvent. Figure 1 shows the separation of tripeptide and tetrapeptide. Disaccharide units (not shown in Figure 1) exhibited a much higher $R_{F}$. Both tripeptide ( $\left.8 \mu \mathrm{moles}\right)$ and tetrapeptide (11 $\mu$ moles) were isolated by removing the appropriate bands of cellulose and extracting them six times with water. The two compounds were submitted to further purification by paper electrophoresis in 0.1 $\mathrm{N}$ formic acid (see Figure 2 in Bricas et al., 1967), followed by filtration in water on Sephadex G-25. Tripeptide and tetrapeptide were found to occur in the ratio 2:3.

B. From E. coli. The lysozyme-degraded rigid layer (see Material and Methods) was filtered in water on the linked Sephadex G-50-G-25 columns. The wall material was eluted as two poorly separated peaks. Preparative paper electrophoreses at $\mathrm{pH} 1.9$ (Savant Instruments apparatus, $150 \mathrm{~min}, 50 \mathrm{v} / \mathrm{cm}$ ) of the high molecular weight fractions yielded four ninhydrin-reactive materials. The less cationic one was found homogeneous by subsequent paper electrophoreses at $\mathrm{pH} 4(2 \mathrm{hr}, 50$ $\mathrm{v} / \mathrm{cm})$, at pH $6.4(2 \mathrm{hr}, 50 \mathrm{v} / \mathrm{cm})$, and by cellulose thinlayer chromatography in solvent III (two successive migrations). This compound was further characterized as the bisdisaccharide peptide dimer, previously designated by Weidel and Pelzer (1964) as fragment $\mathrm{C}_{3}$. Preparative paper electrophoresis at $\mathrm{pH} 1.9$ under the same conditions as above of the low molecular weight fractions yielded three ninhydrin-reactive materials. The less cationic one was found homogeneous at $\mathrm{pH} 6.4$ (150 $\mathrm{min}$, $50 \mathrm{v} / \mathrm{cm})$ but gave rise at $\mathrm{pH} 4(150 \mathrm{~min}, 50 \mathrm{v} / \mathrm{cm})$ to two compounds. The less cationic was characterized as a disaccharide tetrapeptide and the other as a disaccharide tripeptide, i.e., the fragments $C_{6}$ and $C_{5}$, respectively, previously isolated by Weidel and Pelzer (1964). These two latter compounds had chromatographic behaviors identical with those of the two disaccharide peptide monomers found in the unfractionated disaccharide peptide monomer preparation of $B$. megaterium wall (see above). Analyses of the other $E$. coli peptide materials isolated in the course of the preparative electrophoreses just described showed that most of them resulted from the action of the autolytic enzymes on the disaccharide tri- and tetrapeptide monomers and were, in some cases, identical with the fragments obtained by Pelzer (1963) after action of the autolytic system of $E$. coli on compounds " $\mathrm{C}_{3}$," " $\mathrm{C}_{4}$, ," " $\mathrm{C}_{5}$," and " $\mathrm{C}_{6}$." However, among the peptide materials isolated, three were found to contain, besides diaminopimelic acid, lysine and/ or another diamino acid. The presence of lysine and

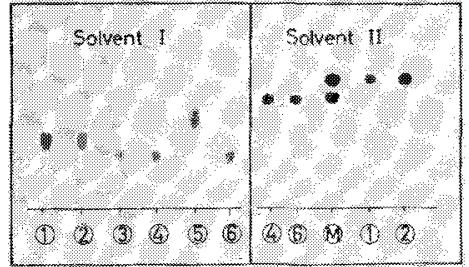

FIGURE 1: Cellulose thin-layer chromatography of natura and synthetic peptides. (1) Tetrapeptide isolated from E. coli; (2) tetrapeptide isolated from B. megaterium; (3) synthetic L-Ala- $\gamma$-D-Glu-(L)-meso-diaminopimelic acid; (4) tripeptide isolated from $B$. megaterium; (5) synthetic L-Ala- $\alpha$-D-Glu-(L)meso-diaminopimelic acid; (6) tripeptide isolated from $E$. coli. (M) Original unfractionated mixture of the tri- and tetrapeptide monomers of $B$. megaterium.

arginine in the pepsin-treated rigid layer of $E$. coli was established by Martin and Frank (1962) who postulated that these amino acids might play a role in the binding of proteins to the outside of the rigid layer. The structure of these unusual peptides now isolated from the rigid layer will be further studied. The isolated disaccharide tripeptide and disaccharide tetrapeptide were separately treated with $N$-acetylmuramyl-L-alanine amidase under standard conditions. Both free tripeptide and tetrapeptide were separated from the free disaccharide units by paper electrophoresis in $0.1 \mathrm{~N}$ formic acid.

Analytical Data. Table I presents the quantitation of total amino acids, $\mathrm{D}$-alanine residues, $\mathrm{N}$ - and $\mathrm{C}$-terminal groups for (1) the synthetic peptide L-Ala- $\gamma-\mathrm{D}-\mathrm{Glu}-(\mathrm{L})$ meso-diaminopimelic acid used as a control, (2) the tripeptide and tetrapeptide monomers isolated from both $E$. coli and B. megaterium, (3) the $E$. coli bisdisaccharide peptide dimer before and after treatment with $\mathrm{KM}$ endopeptidase, an enzyme known to hydrolyze D-Ala(D)-meso-diaminopimelic acid linkages (see Ghuysen et al.,1969). Complete degradation of this dimer was carried out by incubating, for $1 \mathrm{hr}$ at $37^{\circ}, 40 \mathrm{~m} \mu$ moles of substrate with $10 \mu \mathrm{g}$, in protein, of $\mathrm{KM}$ endopeptidase in $30 \mu \mathrm{l}$ (final volume) of $0.01 \mathrm{M}$ Veronal buffer ( $\mathrm{pH}$ 9) (for specific activity, see Ghuysen et al., 1969). A larger amount ( $5 \mu$ moles) of the dimer was enzymatically degraded under identical conditions. Gel filtration on Sephadex G-25, in water, followed by cellulose chromatography in solvent II (two successive migrations) of the degraded products showed that the disaccharide L-Ala$\gamma$-D-Glu-(L)-meso-diaminopimelic acid-(L)-D-Ala monomer only was present. $\mathrm{N}$ - and $\mathrm{C}$-terminal group analyses showed that the enzymatic degradation of the dimer resulted in a $100 \%$ increase of the monoterminal amino group of diaminopimelic acid. Actual yields for the estimation of C-terminal alanine were $77 \%$ with the original dimer and $63 \%$ with the degraded monomer. It should be noted that these $\mathrm{C}$-terminal group quantitations are expressed relative to an alanine standard which was submitted to the same hydrazine treatment. Under the same conditions, and expressed relative to the same standard, hydrazinolysis of the natural tetrapeptides from $B$. megaterium and $E$. coli liberated alanine with a $73 \%$ yield; hydrazinolysis of the synthetic peptide L-Ala-(D)meso-diaminopimelic acid-(D)-L-Ala liberated alanine with a $51 \%$ yield. 


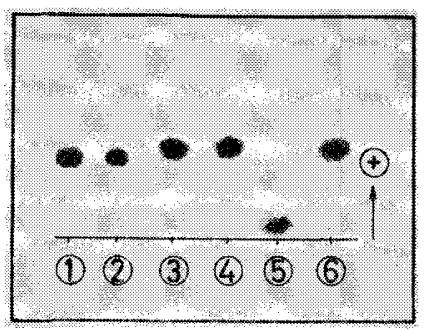

FIGURE 2: Electrophoresis at pH $4(20 \mathrm{~V} / \mathrm{cm} ; 2 \mathrm{hr}$, Pleuger apparatus) of natural and synthetic peptides. For 1-6, see Figure 1.

Table II presents the results of Edman degradations carried out (1) on the synthetic peptides meso-diaminopimelic acid-(D)-L-Ala and L-Ala- $\gamma$-D-Glu-(L)-meso-diaminopimelic acid used as controls and (2) on the $B$. megaterium tripeptide and tetrapeptide and the $E$. coli tripeptide monomers.

Chromatographic and Electrophoretic Properties. Cellulose thin-layer chromatography in solvents I and II and paper electrophoresis at $\mathrm{pH} 4$ (Pleuger apparatus) of the natural tripeptide and tetrapeptide monomers and of the two synthetic tripeptides L-Ala-( $\alpha$ - or $\gamma$-)-D-Glu(L)-meso-diaminopimelic acid are represented in Figures 1 and 2, respectively. Since the $\gamma$-carboxyl group of glutamic has a higher $\mathrm{p} K$ value than that of the $\alpha$-carboxyl group, the tripeptide L-Ala- $\gamma$-D-Glu-(L)-meso-diaminopimelic acid is more anionic than the isomeric $\alpha$ tripeptide under the $\mathrm{pH}$ conditions used. Consequently, the $\gamma$ tripeptide migrates further toward the anode during electrophoresis ( $\mathrm{pH} 4$ ) and has a lower $R_{F}$ on thin-layer plates ( $\mathrm{pH}$ 3.5) than the $\alpha$ isomer.

Electrophoretic Analysis of the Hydrazine-Degraded Peptide Subunits. Both tripeptide and tetrapeptide monomers of $B$. megaterium and $E$. coli and the two synthetic peptides L-Ala-( $\alpha$ - or $\gamma$-)-D-Glu-(L)-meso-diaminopimelic acid were submitted to hydrazinolysis under standard conditions (Ghuysen et al., 1968). Hydrazine was

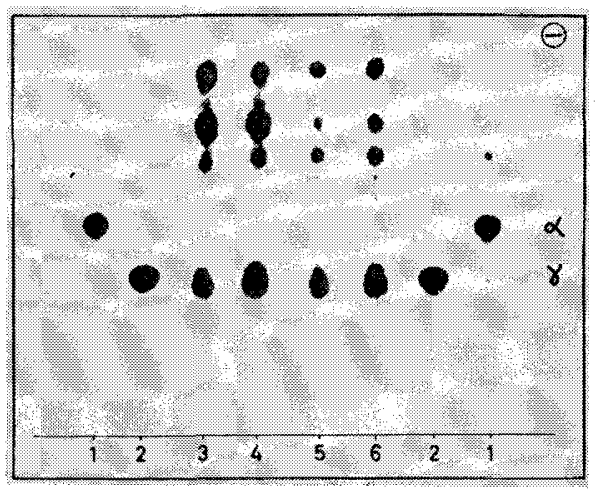

FIGURE 3: Electrophoresis at pH $4(20 \mathrm{~V} / \mathrm{cm}, 2 \mathrm{hr}$, Pleuger apparatus) of ( $\alpha$ - and $\gamma$-) hydrazides of glutamic acid and of hydrazides arising by hydrazinolysis of bacterial peptides. (1) $\alpha$-Hydrazide of glutamic acid; (2) $\gamma$-hydrazide of glutamic acid (Cyclo Chemical Corp.); (3) tripeptide isolated from $B$. megaterium; (4) tripeptide isolated from $E$. coli ; (5) tetrapeptide isolated from $B$. megaterium; (6) tetrapeptide isolated from $E$. coli. Hydrazinolysis of synthetic L-Ala- $\gamma$-D-Glu-(L)meso-diaminopimelic acid and L-Ala- $\alpha$-D-Glu-(L)-meso-diaminopimelic acid gave rise, respectively, to $\gamma$-hydrazide and $\alpha$-hydrazide of glutamic acid (not shown in this figure).

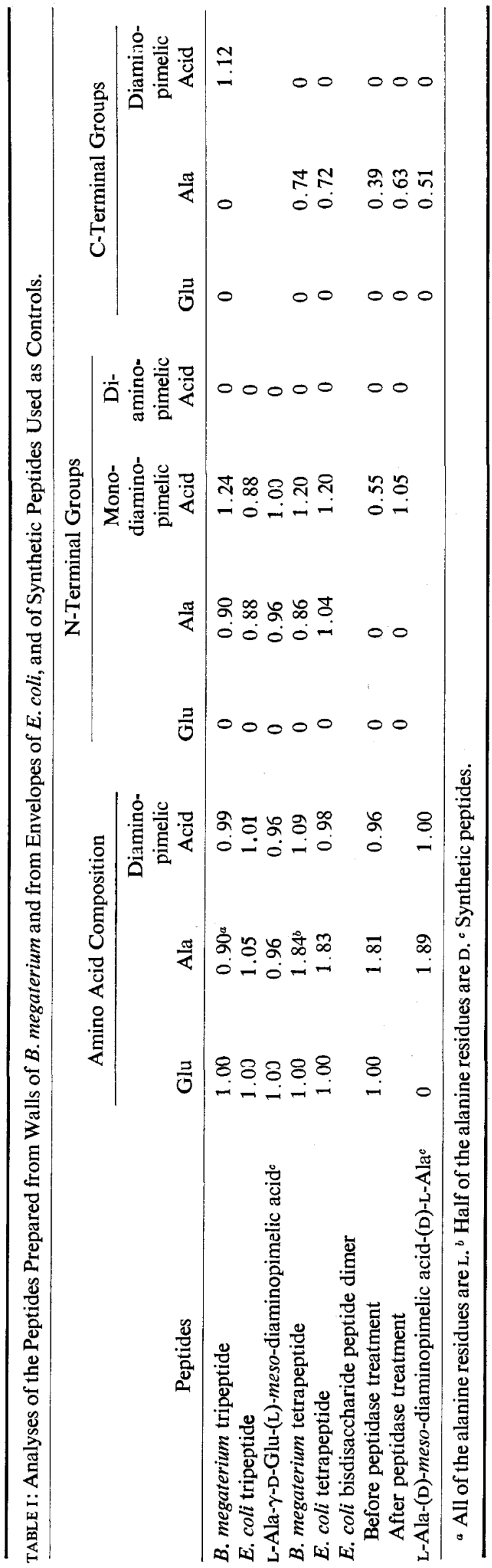


TABle II: Edman Degradation of E. coli and B. megaterium Peptides and of Synthetic Peptides.

\begin{tabular}{|c|c|c|c|c|c|}
\hline & \multirow{2}{*}{$\begin{array}{l}\text { Cycles of } \\
\text { Edman } \\
\text { Degrada- } \\
\text { tion }\end{array}$} & \multicolumn{4}{|c|}{ Terminal Amino Groups ${ }^{a}$} \\
\hline & & Ala & Glu & $\begin{array}{l}\text { Mono- } \\
\text { diaminopimelic } \\
\text { acid }\end{array}$ & $\begin{array}{l}\text { Diamino- } \\
\text { pimelic acid }\end{array}$ \\
\hline \multirow{5}{*}{$\begin{array}{l}\text { Synthetic dipeptide meso- } \\
\text { diaminopimelic acid-(D)-L-Ala } \\
\text { Synthetic tripeptide L-Ala- } \gamma- \\
\text { D-Glu-(L)-meso-diaminopimelic } \\
\text { acid }\end{array}$} & 0 & 0 & 0 & 0 & 877 \\
\hline & 1 & $727^{b}$ & 0 & 0 & 0 \\
\hline & 0 & 955 & 0 & 1000 & 0 \\
\hline & 1 & 70 & 770 & 424 & 0 \\
\hline & 2 & 0 & 166 & 75 & 0 \\
\hline \multirow[t]{3}{*}{ B. megaterium tripeptide } & 0 & 900 & 0 & 1245 & 0 \\
\hline & 1 & 70 & 840 & 412 & 0 \\
\hline & 2 & 0 & 174 & 110 & 0 \\
\hline \multirow[t]{3}{*}{ E. coli tetrapeptide } & 0 & 1040 & 0 & 1200 & 0 \\
\hline & 1 & 20 & 576 & 224 & 0 \\
\hline & 2 & 0 & 115 & 70 & 0 \\
\hline \multirow[t]{3}{*}{ B. megaterium tetrapeptide } & 0 & 860 & 0 & 1200 & 0 \\
\hline & 1 & 17 & 630 & 260 & 0 \\
\hline & 2 & 0 & 206 & 70 & 0 \\
\hline
\end{tabular}

a Data expressed per 1000 total glutamic acid residues or per 1000 total alanine residues for the synthetic dipeptide. ${ }^{b}$ As free L-alanine residue.

removed under vacuum over concentrated $\mathrm{H}_{2} \mathrm{SO}_{4}$. The residues were submitted to electrophoresis at $\mathrm{pH} 4$ (Pleuger apparatus). Detection was made using Folin Ciocalteu reagent-water $(1: 2, v / v)$, followed by exposure to $\mathrm{NH}_{3}$ (Guttmann and Boissonnas, 1960). As shown in Figure 3 the $\gamma$-hydrazide of glutamic acid, but not the $\alpha$ derivative, was present in all the degraded products arising from the natural peptides.

Study of the E. coli Disaccharide Units. Authentic $\beta-1,4-N$-acetylglucosaminyl- $N$-acetylmuramic acid disaccharide isolated from Micrococcus lysodeikticus (LeyhBouille et al., 1966) and the E. coli disaccharide were found indistinguishable with respect to the molar extinction coefficients with the Morgan-Elson reaction (acetamido groups) and with the Park-Johnson reaction (reducing groups).

Degradation of Walls of $B$. megaterium $K M$ by $K M$ Endopeptidase. $\mathrm{N}$ - and C-terminal group analyses of the walls solubilized either by a glycosidase (Streptomyces $F_{1}$ enzyme) or by $\mathrm{KM}$ endopeptidase showed that as a result of the peptidase degradation, all of the diaminopimelic acid residues had one free amino group. ${ }^{2}$ Actually,

${ }^{2}$ In previous studies (Bricas et al., 1967) solubilization of walls of Bacilius megaterium by means of a crude KM endopeptidase working in conjunction with $F_{1}$ endo- $N$-acetylmuramidase, resulted in the liberation of amino groups of meso-diaminopimelic acid only, as well as in the hydrolysis of the glycan portion. In the course of the present investigation, the wall degradation by the purified KM endopeptidase resulted in liberation of amino groups of diaminopimelic acid, the quantitation of which strongly suggests that at the end of the degradation both mesoand DD-diaminopimelic acid occur with one amino group free.
$150 \mathrm{~m} \mu$ moles of monoterminal amino groups of diaminopimelic acid/mg of walls had been unmasked. However, the increase in C-terminal alanine carboxyl groups was only $50 \mathrm{~m} \mu$ moles/mg, a value much lower than expected if D-Ala-(D)-meso-diaminopimelic acid linkages were the only ones to be split.

\section{Discussion}

From the analytical data (Table I), both natural tripeptides evidently have the sequence L-Ala-D-Glu-mesodiaminopimelic acid. Earlier studies (Diringer and Jušic, 1966; Bricas et al., 1967) have shown that glutamic acid is linked to the amino group on the L-carbon of mesodiaminopimelic acid. Cellulose thin-layer chromatography in solvent I (Figure 1) and electrophoresis at pH 4 (Figure 2), i.e., under conditions which distinguish between the two synthetic isomeric tripeptides L-Ala- $(\alpha-$ or $\gamma$-)-D-Glu-(L)-meso-diaminopimelic acid, now establish that in the natural peptide subunits, the $\alpha$-carboxyl group of glutamic acid is free, while its $\gamma$-carboxyl group is linked to diaminopimelic acid. The same conclusion was reached by hydrazinolysis of the natural peptides (Figure 3). This technique had been previously used by Ito and Strominger (1964), by Mirelman and Sharon (1967, 1968) for other bacterial peptides, and, very recently, by Diringer (1968) for the E. coli peptide. The linkage is therefore $\gamma$-D-Glu-(L)-meso-diaminopimelic acid in the bacterial tripeptides as well as in the tetrapeptides. The linkage of the $\gamma$-carboxyl group of glutamic acid to the next amino acid in the sequence thus appears to be a general feature of bacterial peptidoglycans. 


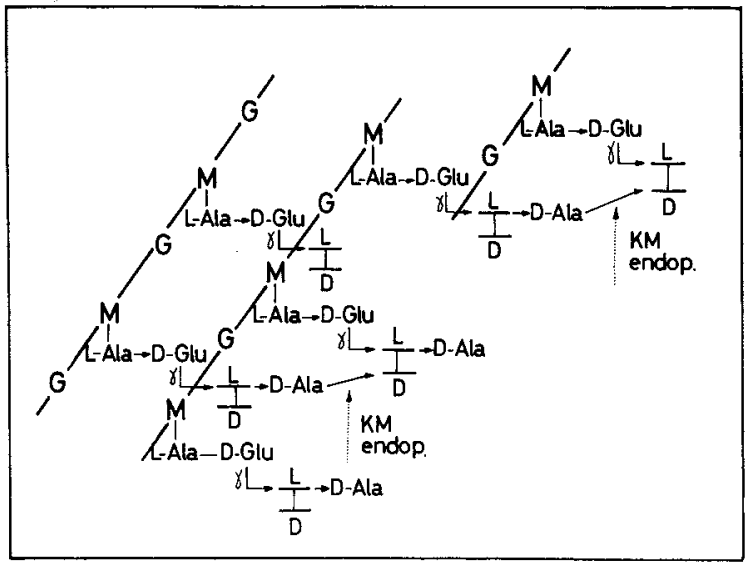

FIGURE 4: A portion of the peptidoglycan monolayer of the $E$. coli envelope and site of action of the Streptomyces KM endopeptidase. I meso-diaminopimelic acid; (G) $N$-acetylglucosamine; (M) $\mathrm{N}$-acetylmuramic acid.

From the analytical data (Table I) both natural tetrapeptides have the sequence L-Ala- $\gamma$-D-Glu-(L)-mesodiaminopimelic acid-D-Ala. Edman degradation (Table II) did not liberate any trace of alanine. Liberation of alanine would have been expected if the terminal D-alanine were linked to the carboxyl group of meso-diaminopimelic acid located on the asymmetric carbon bearing the free amino group. Since this amino group is known to be located on the D-carbon, D-alanine must be linked to the carboxyl group on the L-carbon of meso-diaminopimelic acid. The validity of the demonstration rests on the observed fact that free alanine was liberated with a $73 \%$ yield by Edman degradation of the synthetic mesodiaminopimelic acid-(D)-L-Ala dipeptide. From the foregoing, the sequence of the complete peptide subunits in $E$. coli and B. megaterium is thus L-Ala- $\gamma-\mathrm{D}-\mathrm{Glu}-(\mathrm{L})$ meso-diaminopimelic acid-(L)-D-Ala.

From the analytical data (Table I), the bisdisaccharide peptide dimer is evidently composed of two disaccharide tetrapeptide monomers, with the aforestablished sequence joined through a D-Ala-(D)-meso-diaminopimelic acid linkage. It is also evident that the linkage hydrolyzed by KM endopeptidase is D-Ala-(D)-meso-diaminopimelic acid. Kinetics of hydrolysis (Ghuysen et al., 1969) showed that hydrolysis of this linkage proceeds at the rate of $20 \mathrm{~m} \mu \mathrm{equiv} / \mathrm{hr}$ per $\mu \mathrm{g}$ of enzyme.

From the foregoing, the structure of a major part of the $E$. coli peptidoglycan can be represented as it is shown in Figure 4. One hereby recognizes the presence of tripeptide and tetrapeptide subunits, some of them being joined by a direct link extending from the amino group on the D-carbon of a meso-diaminopimelic acid residue of one subunit to the C-terminal D-Ala residue of another subunit. It must be mentioned that according to a short note of Warth and Strominger (1968), the peptidoglycans in the vegetative cell wall and the spore cortex of $B a$ cillus subtilis have structures identical with those of $E$. coli, with, however, the exception that in some peptide subunits, the carboxyl group on the D-carbon of meso-diaminopimelic is amidated. Finally, tripeptides L-Ala- $\gamma-$ D-Glu(?)-meso-diaminopimelic acid and L-Ala- $\gamma$-D-iso- glutaminyl-(?)-meso-diaminopimelic acid have been characterized in walls of Bacillus licheniformis (Mirelman and Sharon, 1968).

Determination of the peptide cross-linkage in the walls of $B$. megaterium was also attempted. Complications, however, arose from the fact that about $15 \%$ of the total diaminopimelic acid residues are DD and that these residues occur in the native walls with both amino groups unexposed (Bricas et al., 1967). From $\mathrm{N}$ - and C-terminal group analyses, it seems quite plausible that the D-Ala(D)-meso-diaminopimelic acid linkages are not the only important ones and that DD-diaminopimelic acid residues may be involved in another, but yet undetermined, type of linkage.

Another conclusion of the present investigation, which completes previous findings of Primosigh et al. (1961), is that the disaccharide fragments liberated by lysozyme from the $E$. coli rigid layer are the usual $\beta-1,4-N$-acetylglucosaminyl- $N$-acetylmuramic acid units. Indeed, the molar extinction coefficients in the Morgan-Elson reaction (Sharon et al., 1966) and in the Park-Johnson reaction (Ghuysen et al., 1966) allow distinctions between a 1,4- and a 1,6-disaccharide. This further strengthens the hypothesis that the structure of the glycan portion of wall peptidoglycans is consistent throughout the bacterial world.

\section{References}

Bricas, E., Ghuysen, J.-M., and Dezélée, P. (1967), Biochemistry 6, 2598.

Bricas, E., and Nicot, C. (1965), in Proceedings of the 6th European Peptide Symposium, Athens, Sept 1963, Zervas, L., Ed., Oxford, Pergamon.

Bricas, E., Nicot, C., and Lederer, E. (1962), Bull. Soc. Chim. Biol. 44, 1115.

Dezélée, P. (1968), in Proceedings of the 9th European Peptide Symposium, Orsay, April, Bricas, E., Ed., Amsterdam, North Holland Publishing.

Diringer, H. (1968), Z. Naturforsch. $23 b, 883$.

Diringer, H., and Jušić, D. (1966), Z. Naturforsch. 21b, 603.

Ghuysen, J.-M., Bricas, E., Lache, M., and LeyhBouille, M. (1968), Biochemistry 7, 1450.

Ghuysen, J.-M., Bricas, E., Leyh-Bouille, M., Lache, M., and Shockman, G. D. (1967), Biochemistry 6, 2607.

Ghuysen, J.-M., Dierickx, L., Coyette, J., Leyh-Bouille, M., Guinand, M., and Campbell, J. N. (1969), Biochemistry 8, 213 (this issue; paper IV).

Ghuysen, J.-M., Tipper, D. J., and Strominger, J. L. (1966), Methods Enzymol. 8, 685.

Guttmann, S., and Boissonnas, R. A. (1960), Helo. Chim. Acta 43, 200.

Ito, E., and Strominger, J. L. (1964), J. Biol. Chem. 239, 210.

Le Quesne, W. J., and Young, G. T. (1950), J. Chem. Soc., 1959.

Leyh-Bouille, M., Ghuysen, J.-M., Tipper, D. J., and Strominger, J. L. (1966), Biochemistry 5, 3079.

Martin, H. H., and Frank, H. (1962), Z. Naturforsch. $17 b, 190$. 
Mirelman, D., and Sharon, N. (1967), J. Biol. Chem. 242, 3414.

Mirelman, D., and Sharon, N. (1968), J. Biol. Chem. 243, 2279.

Murray, R. G. E., Steed, P., and Elson, H. E. (1965), Can.J. Microbiol. 11, 547.

Pelzer, H. (1963), Z. Naturforsch. 18b, 950.

Pelzer, H. (1965), Arch. Mikrobiol. 50, 334.

Primosigh, J., Pelzer, H., Maass, D., and Weidel, W.
(1961), Biochim. Biophys. Acta 46, 68.

Sharon, N., Osawa, T., Flowers, H. M., and Jeanloz, R. W. (1966), J. Biol. Chem. 241, 223.

Tipper, D. J., Katz, W., Strominger, J. L., and Ghuysen, J.-M. (1967), Biochemistry 6, 921.

Warth, A. D., and Strominger, J. L. (1968), Bacteriol. Proc. 102, 64.

Weidel, W., and Pelzer, H. (1964), Advan. Enzymol. 26, 193. 